\title{
BMJ Open Maternal alcohol use disorder and child school attendance outcomes for non- Indigenous and Indigenous children in Western Australia: a population cohort record linkage study
}

\author{
Katherine Hafekost, ${ }^{1}$ David Lawrence, ${ }^{2}$ Colleen O'Leary, ${ }^{3}$ Carol Bower, ${ }^{1}$ \\ James Semmens, ${ }^{4}$ Stephen R Zubrick ${ }^{1,2}$
}

To cite: Hafekost $\mathrm{K}$, Lawrence D, O'Leary C, et al. Maternal alcohol use disorder and child school attendance outcomes for nonIndigenous and Indigenous children in Western Australia: a population cohort record linkage study. BMJ Open 2017;7:e015650. doi:10.1136/ bmjopen-2016-015650

- Prepublication history and additional material are available. To view these files please visit the journal online (http://dx.doi. org/10.1136/bmjopen-2016015650).

Received 20 December 2016 Revised 19 April 2017 Accepted 23 May 2017

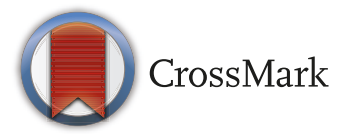

${ }^{1}$ Telethon Kids Institute, The University of Western Australia, Perth, Australia

${ }^{2}$ Graduate School of Education, The University of Western Australia, Perth, Australia ${ }^{3}$ Office of the Chief Psychiatrist, Western Australian Department of Health, Perth, Australia

${ }^{4}$ Faculty of Health Science, Centre for Population Health Research, Curtin University, Perth, Australia

Correspondence to

Katherine Hafekost; katherine. hafekos@@telethonkids.org.au

\section{ABSTRACT}

Objectives Examine the relationship between maternal alcohol use disorder and child school attendance outcomes for non-Indigenous and Indigenous children in Western Australia.

Design Population cohort study.

Setting Routinely collected linked administrative health, education and child protection data.

Participants Those in-scope for the study were women with a birth recorded on the Western Australian Midwives Notification System (1989-2007). Women who had an alcohol-related diagnosis (International Classification of Diseases Revisions 9/10) recorded on the Hospital Morbidity, Mental Health Inpatients and Outpatients, and Drug and Alcohol Office data sets formed the exposed group. The comparison cohort was frequency-matched to the exposed cohort based on maternal age within Indigenous status and child's year of birth.

Primary outcome measure Child's school attendance was obtained from the Department of Education (20082012). Poor attendance was defined as $<80 \%$ attendance for non-Indigenous children and $<60 \%$ attendance for Indigenous children.

Results 11430 exposed children and 26850 unexposed children had a linked attendance record. Maternal alcohol use disorder was significantly associated with increased odds of poor attendance (non-Indigenous: $\mathrm{OR}=1.61$, $95 \% \mathrm{Cl} 1.50$ to 1.74 ; Indigenous: $\mathrm{OR}=1.66,95 \% \mathrm{Cl} 1.54$ to 1.79). With adjustment for maternal and child factors, there was no significant difference between the timing of alcohol diagnosis relative to pregnancy and attendance outcomes. The population attributable fraction was higher in the Indigenous cohort than the non-Indigenous cohort (6.0\% vs $1.3 \%)$.

Conclusions Maternal alcohol use disorder was associated with a significantly increased odds of poor school attendance for non-Indigenous and Indigenous children. There was no significant difference between the timing of diagnoses and odds of poor school attendance. This suggests that the effect of maternal alcohol use disorder may not be driven by the neurodevelopmental effects of alcohol exposure in utero, but may be mediated through family or social factors for which we were unable to adjust.
Strengths and limitations of this study

- A key strength of this analysis is the use of administrative linked data to obtain a large population cohort, which negates the use of retrospective recall of past behaviours and removes participation bias.

- In addition, due to the frequency matching of the comparison group to the exposed cohort, both Indigenous and non-Indigenous estimates could be calculated.

- A limitation of the study is that there are women in the comparison group who may have drunk heavily during the same time period, without receiving an alcohol-related diagnosis, and this would bias estimates towards the null.

- In addition, we lacked information regarding ongoing alcohol use by mothers and were unable to access paternal information, which may have affected outcomes.

\section{BACKGROUND}

It is well recognised that, in order to gain the skills necessary for academic and social success, children need to attend school regularly. ${ }^{12}$ Previous research has identified that absences from school are linked with negative outcomes such as greater risk of poor academic performance, risk-taking behaviours, delinquency and early school dropout. ${ }^{34}$ Of note, children from disadvantaged backgrounds have been identified as more likely to have poor attendance patterns and are disproportionately affected by absences compared with other children. ${ }^{15}$ As poor school attendance in the early years is highly predictive of future absences, ${ }^{1}$ there has been substantial interest in identifying risk factors for absences in the early years of schooling, with the aim of providing additional support and interventions to vulnerable children and families. 
A number of factors have been associated with poor school attendance, including low socioeconomic status and low levels of parental education. ${ }^{13}$ In Australia, Indigenous young people have been identified to have significantly worse attendance and school retention when compared with non-Indigenous children, and it has been suggested that this is a key driver of the gap in academic outcomes between non-Indigenous and Indigenous young people. ${ }^{6-8}$ In addition Moore and McArthur ${ }^{9}$ identified that maternal and family risks, such as family instability, mental illness and drug and alcohol issues, are associated with reduced child participation in school. Poor school attendance can also indicate lack of engagement in schooling, on the part of both the child and their parents or carers.

One group who may be at risk of poor attendance are children of mothers with alcohol use disorders. The teratogenic effects of prenatal alcohol exposure on the developing brain can lead to neurodevelopmental deficits in the child. ${ }^{10}$ At high levels of exposure, and during vulnerable time points during pregnancy, prenatal alcohol exposure has cognitive and behavioural impacts that may affect a child's academic performance and behaviour. ${ }^{11} 12$ In addition to in utero effects of alcohol, children exposed to heavy parental alcohol use postnatally have been identified as having abnormal developmental and social trajectories. This has been attributed to greater family instability, poor family functioning and communication, and greater levels of family stress. In addition, it has been identified that there is a higher risk of child abuse, periods out of home care and mental health problems in the offspring of parents who have heavy alcohol use. ${ }^{13-16}$ Further, comorbidities associated with heavy alcohol use, such as use of other substances, and parental mental and physical health problems, may add to an unstable home environment in which school attendance is not prioritised. ${ }^{1517} 18$ Previous research has identified that parental alcoholism is a risk factor for poor school performance and school absenteeism. ${ }^{19}$ Heavy maternal alcohol consumption is one of a range of factors that are negatively associated with parents' involvement in their children's education. ${ }^{20-22}$ However, little research has examined whether heavy maternal alcohol use specifically and the timing of alcohol use relative to pregnancy impact on a child's school attendance.

Therefore, the primary aim of this project was to determine whether maternal alcohol exposure contributed to poor school attendance, and to quantify the impact on school absenteeism for Indigenous and non-Indigenous young people. In addition, this project sought to determine whether the timing of a maternal alcohol-related diagnosis in relation to pregnancy differentially affected a child's school attendance patterns, with the aim of determining whether this relationship was driven by biological effects of alcohol exposure in utero. In order to investigate these relationships, we made use of routinely collected administrative education, health and child protection data. It was hypothesised that children whose mother had a diagnosis of an alcohol use disorder, which provided a proxy for heavy drinking, would be at greater risk of poor attendance than other children.

\section{METHODS}

\section{Cohort}

This analysis made use of routinely collected Western Australian administrative linked data. All women who had a birth recorded on the Western Australian Midwives Notification System (MNS) between 1983 and 2007 were in-scope for the study ( $\mathrm{n}=253714$ women; non-Indigenous: $n=242956$ and Indigenous: $n=10758) .{ }^{23}$ Cohort selection has been described previously. ${ }^{24}$

Mothers with an alcohol-related diagnosis, based on the International Classification of Diseases Revisions 9/10 (ICD 9/10), were considered to have an alcohol use disorder and constituted the exposed group. An alcohol-related diagnosis provided a proxy for heavy maternal alcohol use. Diagnoses were obtained from the following administrative data sets: Hospital Morbidity Data System, Mental Health Inpatients and Outpatients, and the Drug and Alcohol Office. Diagnoses recorded at any time prior to birth, during pregnancy or postnatally, during the follow-up period, were considered in-scope. Included diagnoses are included in online supplementary material table 1 .

The comparison cohort included a random selection of mothers, identified on the Western Australian MNS, who had no records of an alcohol-related diagnosis. This cohort was frequency-matched to the cohort of exposed mothers based on maternal age within Indigenous status and year of child's birth. The ratio of exposed to comparison mothers was 1:3 and 1:2 for non-Indigenous and Indigenous mothers, respectively. It is important to note that, while maternal alcohol use disorder is a proxy for heavy alcohol use, mothers in the comparison group may have consumed alcohol during the same time period, and some of these mothers may have consumed alcohol at high and at-risk levels without receiving an alcohol-related diagnosis during a hospital or mental health service admission. The final population cohort included 85205 births between 1983 and 2007.

Records were linked by the Western Australian Data Linkage Branch using probabilistic matching. ${ }^{25}$ Ethics approval for the conduct of the study was granted by the Princess Margaret Hospital Human Research Ethics Committee (No 1244/EP), the WA Department of Health Human Research Ethics Committee (No 2011/34) and the Western Australia Aboriginal Health Ethics Committee (No 134-04/06).

\section{Data treatment}

\section{Alcohol exposure}

Both the presence of an alcohol use disorder and the timing of diagnosis relative to pregnancy were of interest. The presence of alcohol use disorder was treated as a binary variable (yes/no). The timing of exposure was 
categorised hierarchically and prioritised diagnoses during pregnancy. Categories included (1) any alcohol-related diagnosis during pregnancy. This may include women who also have a diagnosis before and/or after pregnancy. For women who did not have an alcohol diagnosis recorded during pregnancy, the categories included (2) a diagnosis within the year before pregnancy. As the coding was hierarchical, this group may include women with an additional exposure recorded more than 1 year before pregnancy or any exposure postpregnancy, and (3) a diagnosis up to 1 year after pregnancy. This may include women who had a recorded exposure for more than 1 year before or after pregnancy; and (4) more than 1 year before pregnancy, and this could include exposure greater than 1 year postpregnancy and (5) more than 1 year after pregnancy. This hierarchical coding and the treatment of women with multiple diagnoses throughout the study period is illustrated in online supplementary material table 2 . This has previously been described. ${ }^{24}$

\section{School attendance}

Routinely collected attendance records were obtained from the Western Australian Department of Education. Records were available for the years 2008 through 2012 for children who attended public schools in Western Australia. Attendance data were linked to MNS records for 11430 exposed children and 26850 children in the comparison cohort. Of children with a birth recorded between 1991 and 2006 on the MNS, 16829 (31\%) were not linked to an attendance record. Children without a linked record include those who attended independent or catholic schools during this period and those who had left the Western Australian school system. The linkage rate closely matches the proportion of children attending government schools in Australia in 2012 (71\%). ${ }^{26}$

Absence from school is classified by the Department of Education as either authorised, where the reason provided by the caregiver is considered adequate or legitimate by the principal, or unauthorised. Unauthorised absences refer to those where a student is absent without a reasonable explanation (eg, truancy). Attendance is recorded as the number of half days attended in the first semester of the school year.

Attendance was calculated as the number of half days in attendance as a percentage of the total number of possible half days within the first semester of the school year. In the case where children attended multiple schools, available days and absences were summed. Therefore, there was one attendance record per student per semester, and if children had a record for all in-scope years (2008-2012 inclusive), they would have a total of five attendance records.

It has previously been identified that attendance records are less consistent for years 11 and 12 due to exams and work placements. ${ }^{1}$ Therefore, in an attempt to reduce reporting error, the analysis was restricted to records for children in year 10 (approximately 15 years of age) and below. In addition, records of less than $30 \%$ attendance were removed from the analysis. Removing records of less than $30 \%$ attendance was viewed as a conservative approach to estimating the impact of maternal alcohol use diagnosis on attendance outcomes, and completed with the aim of reducing the impact of children who have left the Western Australian school system or changed schools but continued to be marked absent. This has been identified to be a problem that disproportionately affects Indigenous young people who have very high levels of mobility, including across state borders, often due to cultural reasons. ${ }^{6}$ Of the 917 children who were completely excluded from the analysis, based on an attendance rate of less than $30 \%, 81 \%$ were Indigenous and $45 \%$ had a mother with a maternal alcohol use diagnosis.

In the reported models, 68173 non-Indigenous semester records and 39815 Indigenous semester records were included. The average number of semesters of data per child was 3 , with a maximum of 5 semesters of data per child (ie, 1 semester record per year for 2008-2012 inclusive).

The Department of Education provide the following categories for attendance: regular (90\%-100\% attendance), indicated (80\%-89\% attendance), moderate (60\%-79\% attendance) and severe (less than $60 \%$ attendance). For the purpose of this analysis, poor attendance was defined differently for non-Indigenous and Indigenous cohorts due to the vastly different attendance distributions in these cohorts. In non-Indigenous children, poor attendance equated to an attendance rate less than $80 \%$ (ie, severe or moderate attendance). This was approximately $10 \%$ of the final, non-Indigenous sample. In Indigenous students, the overall attendance rate was substantially lower. As a result, poor attendance was defined as less than $60 \%$ attendance (ie, severe attendance). This was approximately $18 \%$ of the final sample of Indigenous students. As absence from school impacts on a child's learning and academic outcomes, whether authorised or unauthorised, total absence represented the primary outcome.

\section{School information}

Available school information included school type (primary, secondary, combined), child's grade and school area. School area refers to the school's location and categorised based on the Standing Council on School Education and Early Childhood Schools Geographic Location Classification System. These categories include metropolitan, provincial (large urban areas outside of the metropolitan area such as Kalgoorlie Boulder or Geraldton), remote and very remote locations. Further, the number of schools attended within the semester and any history of school suspension was determined. Where multiple schools were attended within a single semester, school information was obtained from the school with most days attended. 
Mother's sociodemographic information

Maternal demographic, mental health and drug use information was obtained from the MNS, Hospital Morbidity Data System (hospital inpatients) and Mental Health Inpatient and Outpatients data sets. Demographic information included in this analysis was predominately from the time of the child's birth, and included socioeconomic status, maternal age at child's birth, parity, Indigenous status, health service region (rural or metropolitan) and maternal marital status. In addition, record of any mental health problem or illicit drug use (ICD 9/10 codes), excluding those related to alcohol use, was available.

\section{Child variables}

In addition to school information, child gender, preterm status ( $<37$ weeks' gestation) and presence of fetal alcohol spectrum disorder and/or an intellectual disability were obtained from the MNS, Western Australian Register of Developmental Anomalies, and Intellectual Disability database, respectively. ${ }^{23}$ Further, proportion of optimal birth weight was calculated by comparing observed with optimal birth weight. This measure, which provides an indication of fetal growth, takes into account sex, gestational age, maternal height and parity. ${ }^{27}$ Low proportion of optimal birth weight was defined as below the 10th percentile. Finally, a record of contact with child protective services, which was defined as a substantiated maltreatment allegation or period of out-of-home care, was obtained from the Department of Child Protection and Family Support.

\section{Statistical analysis}

All analysis was carried out using SAS V.9.3.

Comparisons between exposed and comparison cohorts were assessed for significance using $\mathrm{X}^{2}$ tests.

As attendance distributions were highly skewed, and with the aim of reducing the impact of children with very low attendance records who were not attending school, poor attendance was treated as a binary outcome (non-Indigenous: $<80 \%$ days attended, Indigenous: $<60 \%$ days attended).

Hierarchical generalised linear mixed models with a logit link were used to analyse the relationship between poor attendance and maternal alcohol use, and sociodemographic and school characteristics, with models nested at the child and family level. Possible maternal, child and school covariates were tested in a univariate model and those that were significant $(\alpha<0.05)$ were tested for significance in multivariate models. The most parsimonious model was reported. Indigenous and non-Indigenous data were modelled separately to align with the aims of the study. All models included the frequency matching variables (ie, maternal age and baby year of birth).

In addition, generalised linear models were used to estimate the impact of maternal alcohol use on the number of days absent (total, authorised and unauthorised) within the exposed cohort. In order to estimate this, model parameters were used to score the data. This was completed twice, once with the data in its original form and once with alcohol exposure set to 0 . The difference between the estimated number of days absent was calculated. The difference between these two estimates was used to calculate the percentage of total absences that could be attributed to maternal alcohol use exposure.

The population attributable risk fraction, which is the difference in the rate of non-attendance between the exposed and comparison cohorts, was calculated. The population attributable risk fraction was calculated by adjusting for the matching ratio and multiplying up to the Western Australian population.

\section{Sensitivity analysis}

The minimum threshold for attendance (ie, 30\%) was not based on a predefined cut-point, and therefore in order to test the stability of results, we reran the final models using different minimum cut-offs for attendance. We examined two alternative models, one with a sample of children who attended a minimum of $20 \%$ of days during the semester, and a second model that included children who attended a minimum of $40 \%$ of available days during the semester. We assessed the change in the strength and direction of results compared with the final models.

\section{RESULTS}

Within the non-Indigenous cohort, a higher proportion of mothers in the comparison cohort were married $(84.2 \%$ vs $72.2 \%)$ and were in the highest $25 \%$ of socioeconomic status ( $15.2 \%$ vs $9.5 \%)$ at the time of the child's birth compared with those mothers in the exposed cohort. A substantially greater proportion of non-Indigenous mothers in the exposed cohort had a mental health diagnosis compared with comparison mothers $53.5 \%$ vs $11.0 \%)$ and/or a record of illicit drug use $(40.7 \%$ vs $2.2 \%)$.

Within the Indigenous cohort, there was little difference between the socioeconomic status, health service region and maternal age at child's birth of exposed and comparison cohort mothers. A greater proportion of exposed mothers had a mental health record $(32.4 \%$ vs $12.9 \%)$ or a record of illicit drug use $(27.0 \%$ vs $6.0 \%)$ than the comparison cohort. While numbers were low, fetal alcohol spectrum disorder and intellectual disability were higher in the exposed group when compared with those whose mother did not have an alcohol use disorder diagnosis for both Indigenous and non-Indigenous cohorts (table 1).

When comparing the exposed and comparison children within Indigenous status, there were similar proportions of students in schools in metropolitan, provincial and remote schools (table 2). However, there were differences between Indigenous and non-Indigenous cohorts with a higher proportion of Indigenous students in remote and very remote locations compared with non-Indigenous students (44\% vs 9\%). A greater proportion of exposed than comparison children attended multiple schools and 


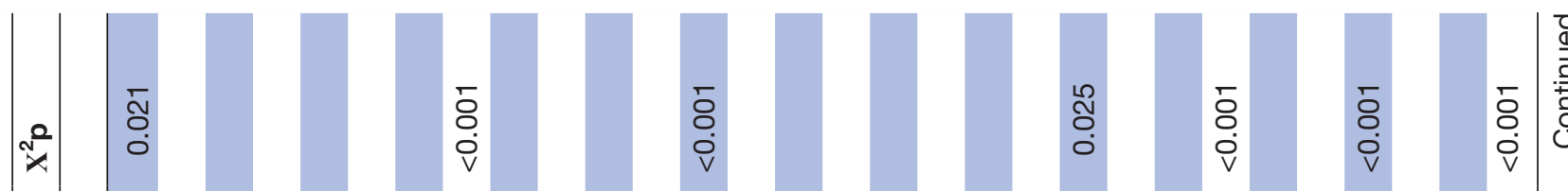

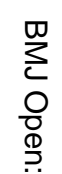

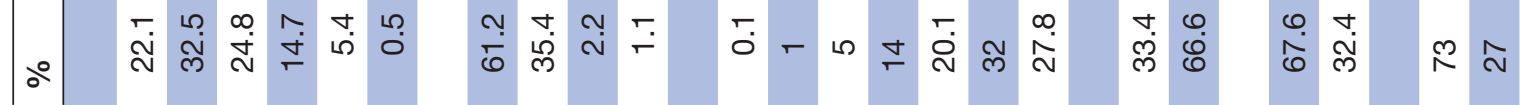

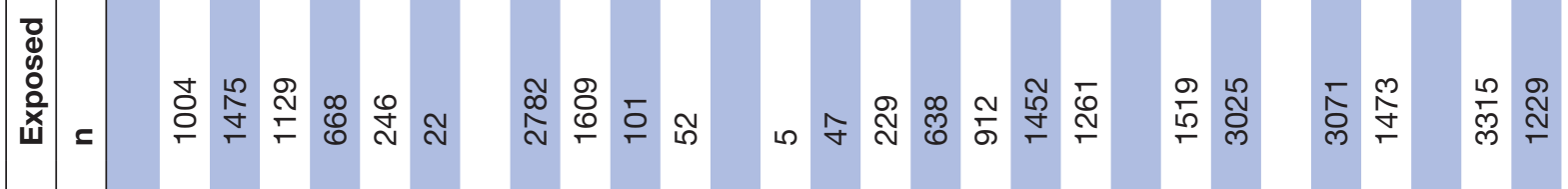

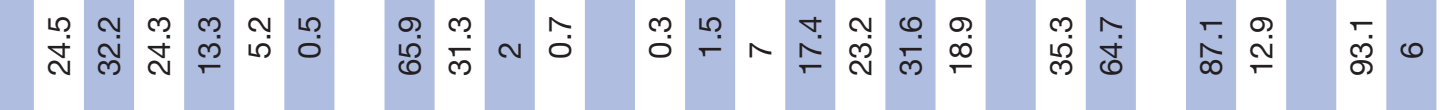

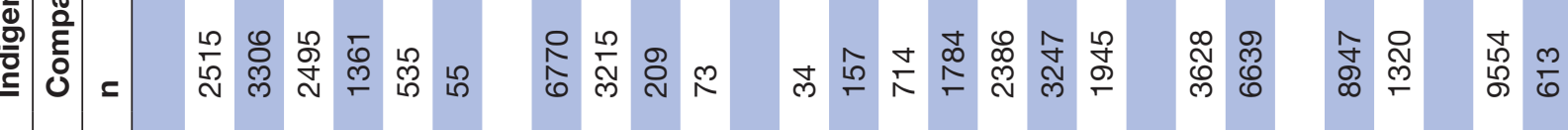

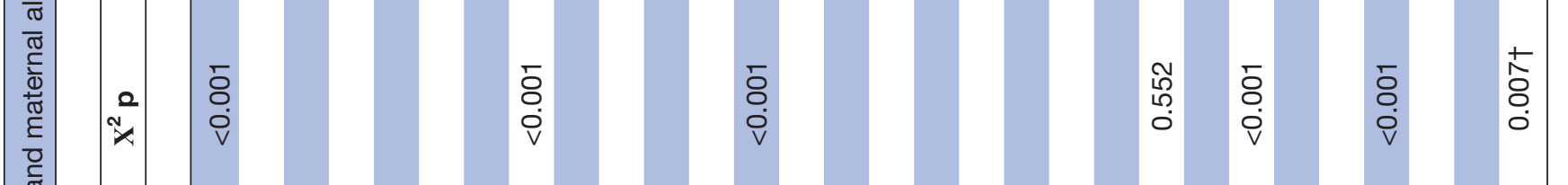

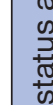

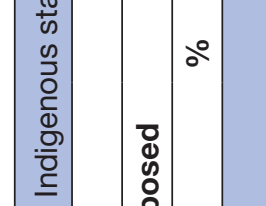

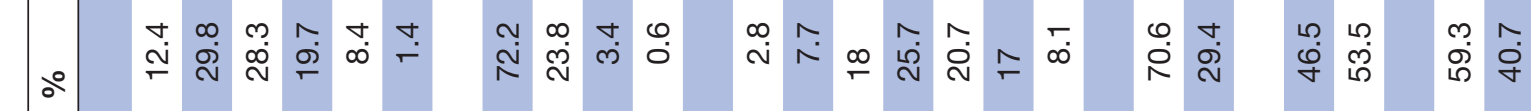

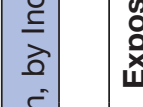

=

芯总

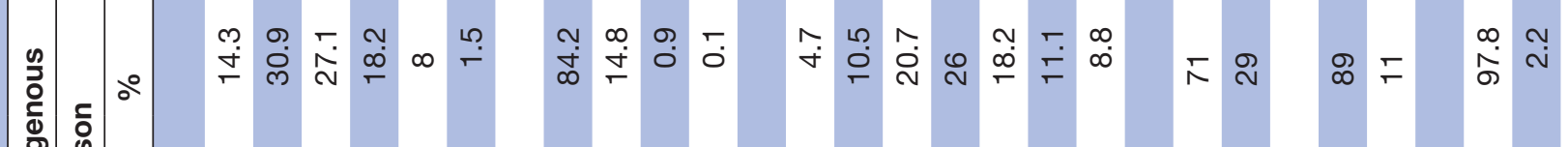

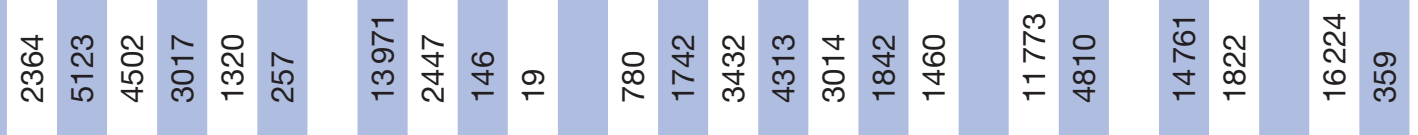

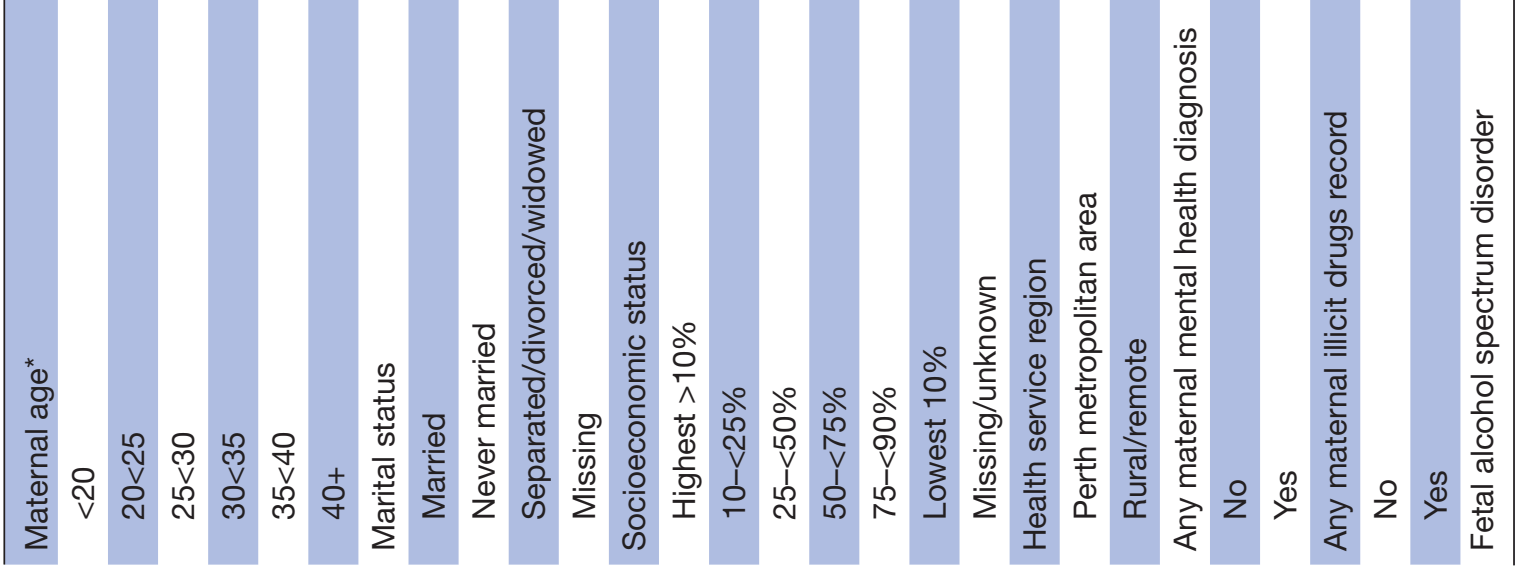




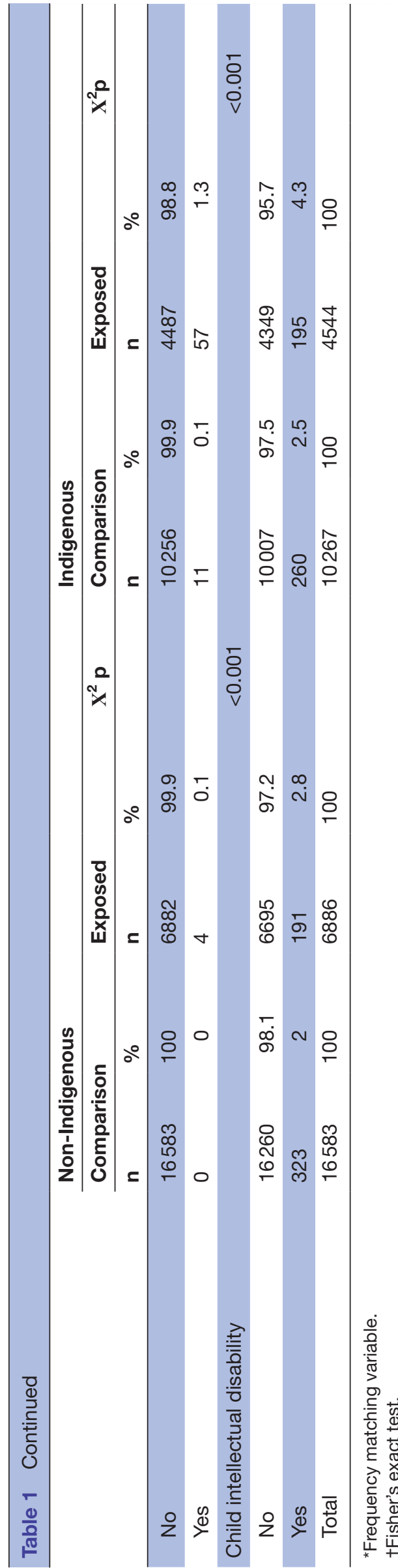

had a history of a school suspension. This was consistent between non-Indigenous (more than one school: 6.8\% exposed vs $3.9 \%$ comparison; suspension: $10.8 \%$ vs $5.6 \%$ ) and Indigenous cohorts (more than one school: $16.1 \%$ exposed vs $13.1 \%$ comparison; suspension: $20.7 \%$ vs $15.3 \%)$. It is important to note that the school-level data reported in table 2 include multiple records per child.

\section{Attendance profiles by Indigenous status and maternal alcohol use exposure}

Table 3 provides the distribution of students across attendance categories by Indigenous status and presence of a maternal alcohol use disorder. Within Indigenous status, those children exposed to a maternal alcohol use disorder were significantly more likely to be classified as being in the 'severe' attendance category when compared with those in the comparison cohort (non-Indigenous: $1.9 \%$ vs $4.8 \%, \mathrm{p}<0.001$; Indigenous: $19.7 \%$ vs $30.5 \%, \mathrm{p}<0.001)$.

Indigenous students had substantially worse attendance than non-Indigenous students (regular attendance: $30 \%$ vs $69 \%, \mathrm{p}<0.001)$. The median number of authorised absences was 4 days in both non-Indigenous (comparison: 4, Q1-Q3=1.3-8.0; exposed: 4.3, Q1-Q3=1.5-9.5) and Indigenous cohorts (comparison: 4.1, Q1-Q3=1.0-10.1; exposed: 3.7, Q1-Q3=1.0-10.1). The median number of days classified as unauthorised absences was substantially higher in the Indigenous cohort (comparison: 9.0 Q1Q3=2.1-24.2; exposed: 14.7, Q1-Q3=4.0-35.9) compared with the non-Indigenous cohort (comparison: 0.0, Q1$\mathrm{Q} 3=0.0-2.6$; exposed: 1.1, Q1-Q3=0.0-5.3). Again, these data are reported at the semester level, and as a result there are multiple records per child.

\section{Predictors of poor attendance}

The unadjusted odds of poor attendance associated with maternal alcohol use disorder were higher in the non-Indigenous cohort $(\mathrm{OR}=2.11,95 \%$ CI 1.98 to 2.26$)$ than in the Indigenous cohort $(\mathrm{OR}=1.70,95 \% \mathrm{CI} 1.58$ to 1.82). When maternal and child factors were accounted for, children whose mother had an alcohol use disorder were more likely to be classified as having poor attendance compared with other children (non-Indigenous: $\mathrm{OR}=1.61,95 \% \mathrm{CI} 1.50$ to 1.74 ; Indigenous: $\mathrm{OR}=1.66$, $95 \%$ CI 1.54 to 1.79$)$. When the model was adjusted for maternal and child factors, the odds of poor attendance did not significantly differ with the timing of alcohol diagnosis relative to pregnancy in non-Indigenous and Indigenous cohorts. However, a diagnosis at any time point was associated with a significantly elevated odds of poor attendance.

A number of sociodemographic factors were significantly associated with poor school attendance (tables 4 and 5). In the non-Indigenous cohort, there were increasing odds of poor attendance with increasing socioeconomic disadvantage. Mothers under the age of 20 at the time of the child's birth were at greater risk of having a child with poor attendance compared with those in the 20-25 years old age group $(<20$ years: $\mathrm{OR}=1.47$ 
Table 2 School factors for all linked records, year 10 or below, by Indigenous status and maternal alcohol use disorder exposure

\begin{tabular}{|c|c|c|c|c|c|c|c|c|c|c|}
\hline & \multicolumn{5}{|c|}{ Non-Indigenous } & \multicolumn{5}{|c|}{ Indigenous } \\
\hline & \multicolumn{2}{|c|}{ Comparison } & \multicolumn{2}{|c|}{ Exposed } & \multirow[t]{2}{*}{$X^{2} p$} & \multicolumn{2}{|c|}{ Comparison } & \multicolumn{2}{|c|}{ Exposed } & \multirow[t]{2}{*}{$X^{2} p$} \\
\hline & $\mathbf{n}$ & $\%$ & $\mathbf{n}$ & $\%$ & & $\mathbf{n}$ & $\%$ & $\mathbf{n}$ & $\%$ & \\
\hline Number of years per child & & & & & 0.058 & & & & & 0.014 \\
\hline 1 & 2699 & 18.2 & 1083 & 17.6 & & 1710 & 18.7 & 821 & 20.3 & \\
\hline 2 & 2570 & 17.3 & 979 & 15.9 & & 1558 & 17.0 & 704 & 17.4 & \\
\hline 3 & 2418 & 16.3 & 1037 & 16.8 & & 1447 & 15.8 & 658 & 16.3 & \\
\hline 4 & 2268 & 15.3 & 974 & 15.8 & & 1452 & 15.8 & 660 & 16.3 & \\
\hline 5 & 4878 & 32.9 & 2090 & 33.9 & & 2998 & 32.7 & 1205 & 29.8 & \\
\hline School type & & & & & $<0.001$ & & & & & $<0.001$ \\
\hline Combined & 1797 & 3.7 & 961 & 4.7 & & 3254 & 10.9 & 1475 & 11.5 & \\
\hline Primary & 33145 & 68.3 & 13391 & 65.3 & & 18316 & 61.1 & 7839 & 60.9 & \\
\hline Secondary & 12466 & 25.7 & 5499 & 26.8 & & 7000 & 23.4 & 2819 & 21.9 & \\
\hline Other & 1147 & 2.4 & 647 & 3.2 & & 1395 & 4.7 & 735 & 5.7 & \\
\hline School area & & & & & $<0.001$ & & & & & $<0.001$ \\
\hline Metropolitan & 31540 & 65.0 & 12675 & 61.8 & & 9978 & 33.3 & 3701 & 28.8 & \\
\hline Provincial & 46 & 26.4 & 5892 & 28.8 & & 7265 & 24.2 & 2916 & 22.7 & \\
\hline $\begin{array}{l}\text { Remote, very remote, } \\
\text { school closed }\end{array}$ & 4181 & 8.6 & 1913 & 9.3 & & 12722 & 42.5 & 6251 & 48.6 & \\
\hline Number of schools attended & & & & & $<0.001$ & & & & & $<0.001$ \\
\hline One school & 46700 & 96.2 & 19099 & 93.2 & & 26066 & 87 & 10801 & 83.9 & \\
\hline Two schools & 1771 & 3.7 & 1312 & 6.4 & & 3461 & 11.6 & 1823 & 14.2 & \\
\hline Three or more schools & 84 & 0.2 & 87 & 0.4 & & 438 & 1.5 & 244 & 1.9 & \\
\hline Suspension record & & & & & $<0.001$ & & & & & $<0.001$ \\
\hline No & 45810 & 94.4 & 18277 & 89.2 & & 25376 & 84.7 & 10203 & 79.3 & \\
\hline Yes & 2745 & 5.6 & 2221 & 10.8 & & 4589 & 15.3 & 2665 & 20.7 & \\
\hline
\end{tabular}

Note: One semester record per child for each year attended within follow-up period.

95\% CI 1.33 to 1.63$)$. In contrast, having a mother over the age of 25 appeared protective. Higher parity was significantly associated with poor attendance outcomes (three or more siblings: OR=2.65, 95\% CI 2.36 to 2.98), as was being unmarried at the time of the child's birth (never married: $\mathrm{OR}=1.38,95 \%$ CI 1.27 to 1.50 ; separated, widowed or divorced: $\mathrm{OR}=1.53,95 \%$ CI 1.25 to 1.88$)$. A maternal mental health diagnosis $(\mathrm{OR}=1.20,95 \% \mathrm{CI} 1.11$ to 1.30 ) or a record of contact with the child protection system (OR=1.12, 95\% CI 1.00 to 1.24$)$ were also associated with elevated risk.

In the Indigenous cohort, maternal age at birth $(<20$ years: $\mathrm{OR}=1.45,95 \% \mathrm{CI} 1.30$ to 1.60 ), socioeconomic status (most disadvantaged 10\%: OR=1.44, 95\% CI 1.24 to

Table 3 Attendance categories for all linked records year 10 and below, by Indigenous status and maternal alcohol use disorder exposure

\begin{tabular}{lllllllll}
\hline & \multicolumn{2}{l}{ Non-Indigenous } & \multicolumn{3}{l}{ Indigenous } \\
\cline { 2 - 10 } & \multicolumn{2}{l}{ Comparison } & Exposed & \multicolumn{2}{l}{ Comparison } & \multicolumn{2}{l}{ Exposed } \\
\cline { 2 - 10 } & $\mathbf{n}$ & $\mathbf{n}$ & $\mathbf{n}$ & $\%$ & $\mathbf{n}$ & $\%$ & $\mathbf{n}$ & $\%$ \\
\hline Regular (90\%-100\% attendance) & 35163 & 72.4 & 12459 & 60.8 & 9769 & 32.6 & 3254 & 25.3 \\
Indicated (80\%-89\% attendance) & 9295 & 19.1 & 4697 & 22.9 & 6915 & 23.1 & 2382 & 18.5 \\
Moderate (60\%-79\% attendance) & 3199 & 6.6 & 2354 & 11.5 & 7366 & 24.6 & 3309 & 25.7 \\
Severe (<60\% attendance) & 898 & 1.9 & 988 & 4.8 & 5915 & 19.7 & 3923 & 30.5 \\
Total & 48555 & 100.0 & 20498 & 100.0 & 29965 & 100.0 & 12868 & 100.0 \\
\hline
\end{tabular}

Note: One semester per child per year of school attended within follow-up period. 
Table 4 Adjusted ORs for alcohol use disorder exposure and demographic factors significantly associated with $<80 \%$ attendance, non-Indigenous

\begin{tabular}{|c|c|c|c|}
\hline & & OR $^{*}$ & $95 \% \mathrm{Cl}$ \\
\hline \multirow[t]{6}{*}{ Alcohol diagnosis } & No alcohol diagnosis & Ref & \\
\hline & During pregnancy & 1.45 & 1.11 to 1.88 \\
\hline & $>1$ year postpregnancy & 1.59 & 1.45 to 1.74 \\
\hline & $>1$ year prepregnancy & 1.65 & 1.49 to 1.83 \\
\hline & Up to 1 year postpregnancy & 1.39 & 1.06 to 1.81 \\
\hline & Up to 1 year prepregnancy & 1.54 & 1.27 to 1.87 \\
\hline \multirow[t]{6}{*}{ Maternal age at child's birth } & $20-<25$ years & Ref & \\
\hline & $<20$ years & 1.47 & 1.33 to 1.63 \\
\hline & $25-<30$ years & 0.83 & 0.76 to 0.91 \\
\hline & $30-<35$ years & 0.73 & 0.66 to 0.81 \\
\hline & $35-<40$ years & 0.68 & 0.59 to 0.79 \\
\hline & $40+$ years & 0.80 & 0.60 to 1.05 \\
\hline \multirow[t]{3}{*}{ Marital status } & Married & Ref & \\
\hline & Never married & 1.38 & 1.27 to 1.50 \\
\hline & Separated, widowed, divorced & 1.53 & 1.25 to 1.88 \\
\hline \multirow[t]{7}{*}{ Socioeconomic status } & Most advantaged $>10 \%$ & Ref & \\
\hline & Second group $10 \%$ to $<25 \%$ & 1.21 & 0.94 to 1.57 \\
\hline & Third group $25 \%$ to $<50 \%$ & 1.42 & 1.12 to 1.80 \\
\hline & Fourth group $50 \%$ to $<75 \%$ & 1.57 & 1.24 to 1.99 \\
\hline & Fifth group $75 \%$ to $<90 \%$ & 1.78 & 1.41 to 2.26 \\
\hline & Most disadvantaged bottom $10 \%$ & 1.90 & 1.50 to 2.42 \\
\hline & Unknown & 1.37 & 1.06 to 1.77 \\
\hline \multirow[t]{4}{*}{ Parity } & 0 & Ref & \\
\hline & 1 & 1.29 & 1.19 to 1.41 \\
\hline & 2 & 1.81 & 1.63 to 2.00 \\
\hline & $3+$ & 2.65 & 2.36 to 2.98 \\
\hline \multirow[t]{2}{*}{ Percentage of optimal birth weight } & Greater or equal to 10 th percentile & Ref & \\
\hline & Less than 10th percentile & 1.24 & 1.13 to 1.36 \\
\hline \multirow[t]{2}{*}{ Any maternal mental health record } & No & Ref & \\
\hline & Yes & 1.20 & 1.11 to 1.30 \\
\hline \multirow[t]{2}{*}{ Child protection contact } & No & Ref & \\
\hline & Yes & 1.12 & 1.00 to 1.24 \\
\hline
\end{tabular}

${ }^{*}$ Adjusted for all other variables and baby year of birth (matching variable).

1.67 ) and parity (three or more siblings: $\mathrm{OR}=1.85,95 \% \mathrm{CI}$ 1.64 to 2.08) were associated with increased odds of poor attendance. In addition, Indigenous children born in rural health service regions were at greater odds of being classified as having poor attendance compared with Indigenous children born in metropolitan regions (rural: $\mathrm{OR}=1.52,95 \% \mathrm{CI} 1.40$ to 1.64 ). A maternal mental health diagnosis or a record of illicit drug use appeared protective in this cohort (mental health diagnosis: $\mathrm{OR}=0.91$, $95 \%$ CI 0.83 to 0.99 ; illicit drug record: $\mathrm{OR}=0.85,95 \%$ CI 0.76 to 0.95 ).

There were a number of school factors that were significantly associated with poor attendance in both the
non-Indigenous and Indigenous cohorts (tables 6 and 7). Children in secondary school were at greater odds of poor attendance than children in primary school (non-Indigenous $\mathrm{OR}=1.36$, 95\% CI 1.19 to 1.56 ; Indigenous: $\mathrm{OR}=1.66,95 \% \mathrm{CI} 1.51$ to 1.81 ). In addition, those attending a school in remote areas had a greater risk of poor attendance compared with other children in both non-Indigenous (remote/very remote: $\mathrm{OR}=1.25,95 \% \mathrm{CI}$ 1.12 to 1.40 ) and Indigenous cohorts (remote: $\mathrm{OR}=1.32$, $95 \%$ CI 1.18 to 1.47 ; very remote: $\mathrm{OR}=1.62,95 \%$ CI 1.45 to 1.80). A higher number of schools attended within the semester and a suspension record (non-Indigenous: $\mathrm{OR}=2.3695 \% \mathrm{CI} 2.19$ to 2.54; Indigenous: $\mathrm{OR}=1.43$ 
Table 5 Adjusted ORs for alcohol use disorder exposure and demographic factors significantly associated with $<60 \%$ attendance, Indigenous

\begin{tabular}{|c|c|c|c|}
\hline & & OR $^{*}$ & $95 \% \mathrm{Cl}$ \\
\hline \multirow[t]{6}{*}{ Alcohol diagnosis } & No alcohol diagnosis & Ref & \\
\hline & During pregnancy & 1.76 & 1.48 to 2.08 \\
\hline & $>1$ years postpregnancy & 1.70 & 1.54 to 1.87 \\
\hline & $>1$ year prepregnancy & 1.62 & 1.43 to 1.83 \\
\hline & Up to 1 year postpregnancy & 1.42 & 1.12 to 1.78 \\
\hline & Up to 1 year prepregnancy & 1.66 & 1.38 to 2.00 \\
\hline \multirow[t]{6}{*}{ Maternal age at child's birth } & $20-<25$ years & Ref & \\
\hline & $<20$ years & 1.45 & 1.30 to 1.60 \\
\hline & $25-<30$ years & 0.81 & 0.74 to 0.90 \\
\hline & $30-<35$ years & 0.77 & 0.69 to 0.87 \\
\hline & $35-<40$ years & 0.79 & 0.67 to 0.94 \\
\hline & $40+$ years & 1.03 & 0.65 to 1.61 \\
\hline \multirow[t]{3}{*}{ Marital status } & Married & Ref & \\
\hline & Never married & 1.16 & 1.07 to 1.25 \\
\hline & Separated, widowed, divorced & 0.96 & 0.75 to 1.22 \\
\hline \multirow[t]{2}{*}{ Any maternal illicit drug record } & No & Ref & \\
\hline & Yes & 0.85 & 0.76 to 0.95 \\
\hline \multirow[t]{2}{*}{ Any maternal mental health record } & No & Ref & \\
\hline & Yes & 0.91 & 0.83 to 0.99 \\
\hline \multirow[t]{2}{*}{ Health region } & Metro & Ref & \\
\hline & Rural & 1.52 & 1.40 to 1.64 \\
\hline \multirow[t]{5}{*}{ Socioeconomic status } & $>50 \%$ most advantaged & Ref & \\
\hline & $50 \%$ to $<75 \%$ & 1.09 & 0.93 to 1.28 \\
\hline & $75 \%$ to $<90 \%$ & 1.25 & 1.07 to 1.45 \\
\hline & Most disadvantaged $10 \%$ & 1.44 & 1.24 to 1.67 \\
\hline & Unknown & 1.95 & 1.68 to 2.27 \\
\hline \multirow[t]{4}{*}{ Parity } & 0 & Ref & \\
\hline & 1 & 1.17 & 1.05 to 1.30 \\
\hline & 2 & 1.25 & 1.11 to 1.41 \\
\hline & $3+$ & 1.85 & 1.64 to 2.08 \\
\hline
\end{tabular}

*Adjusted for all other variables and baby year of birth (matching variable)

$95 \%$ CI 1.33 to 1.52 ) were also positively associated with likelihood of poor attendance.

\section{Impact of maternal alcohol use on attendance rates}

The population attributable fraction for poor attendance with any maternal alcohol diagnosis was estimated to be $1.3 \%$ (95\% CI 1.2 to 1.5 ) in the non-Indigenous population and $6.0 \%$ (95\% CI 5.0 to 6.7 ) in the Indigenous population. It is important to note that poor attendance was defined as less than $80 \%$ attendance for non-Indigenous students and less than $60 \%$ attendance for Indigenous students.

When the impact was estimated within the exposed cohort, maternal alcohol use disorder accounted for approximately $15 \%$ of the total days absent in both Indigenous and non-Indigenous children $(16 \%$ and
$14 \%$, respectively). Further, maternal alcohol use accounted for $30 \%$ of the unauthorised absences in non-Indigenous children and $21 \%$ in Indigenous children. Maternal alcohol use disorder accounted for $9 \%$ and $2 \%$ of the authorised absences in exposed non-Indigenous and Indigenous children, respectively.

\section{Sensitivity analysis}

Sensitivity analysis, which made use of alternative minimum attendance thresholds for inclusion in modelling, suggested that the final models were relatively stable. The average difference between the results of these models was less than $10 \%$, and the use of different minimum attendance thresholds did not change the direction or interpretation of the final models. 
Open Access

Table 6 Adjusted ORs for alcohol use disorder exposure, demographic and school factors significantly associated with $<80 \%$ attendance, non-Indigenous mothers

\begin{tabular}{|c|c|c|c|}
\hline & & OR $^{*}$ & $95 \% \mathrm{Cl}$ \\
\hline \multirow[t]{6}{*}{ Alcohol diagnosis } & No alcohol diagnosis & Ref & \\
\hline & During pregnancy & 1.52 & 1.17 to 1.98 \\
\hline & $>1$ years postpregnancy & 1.55 & 1.41 to $1.7 C$ \\
\hline & $>1$ year prepregnancy & 1.62 & 1.46 to 1.80 \\
\hline & Up to 1 year postpregnancy & 1.36 & 1.04 to $1.7 \varepsilon$ \\
\hline & Up to 1 year prepregnancy & 1.58 & 1.30 to 1.92 \\
\hline \multirow[t]{3}{*}{ Marital status } & Married & Ref & \\
\hline & Never married & 1.33 & 1.22 to 1.45 \\
\hline & Separated, widowed, divorced & 1.52 & 1.24 to $1.8 \varepsilon$ \\
\hline \multirow[t]{7}{*}{ Socioeconomic status } & Most advantaged $>10 \%$ & Ref & \\
\hline & Second group $10 \%$ to $<25 \%$ & 1.18 & 0.91 to 1.53 \\
\hline & Third group $25 \%$ to $<50 \%$ & 1.36 & 1.07 to 1.72 \\
\hline & Fourth group $50 \%$ to $<75 \%$ & 1.48 & 1.17 to 1.87 \\
\hline & Fifth group $75 \%$ to $<90 \%$ & 1.68 & 1.32 to 2.13 \\
\hline & Most disadvantaged bottom $10 \%$ & 1.79 & 1.41 to $2.2 \varepsilon$ \\
\hline & Unknown & 1.30 & 1.01 to 1.68 \\
\hline \multirow[t]{2}{*}{ Any maternal mental health record } & No & Ref & \\
\hline & Yes & 1.20 & 1.11 to 1.30 \\
\hline \multirow[t]{6}{*}{ Maternal age at child's birth } & $20-<25$ years & Ref & \\
\hline & $<20$ years & 1.42 & 1.29 to 1.58 \\
\hline & $25-<30$ years & 0.87 & 0.79 to 0.95 \\
\hline & $30-<35$ years & 0.78 & 0.70 to 0.86 \\
\hline & $35-<40$ years & 0.76 & 0.66 to $0.8 \varepsilon$ \\
\hline & $40+$ years & 0.91 & 0.69 to 1.21 \\
\hline \multirow[t]{4}{*}{ Parity } & 0 & Ref & \\
\hline & 1 & 1.26 & 1.16 to 1.37 \\
\hline & 2 & 1.73 & 1.56 to 1.92 \\
\hline & $3+$ & 2.47 & 2.19 to 2.78 \\
\hline \multirow[t]{3}{*}{ Number of schools } & One school & Ref & \\
\hline & Two schools & 2.41 & 2.20 to 2.64 \\
\hline & Three or more schools & 3.48 & 2.49 to 4.87 \\
\hline \multirow[t]{4}{*}{ School type } & Primary & Ref & \\
\hline & Combined & 1.11 & 0.94 to 1.31 \\
\hline & Secondary & 1.36 & 1.19 to 1.56 \\
\hline & Other & 0.97 & 0.81 to 1.18 \\
\hline \multirow[t]{3}{*}{ School area } & Metropolitan & Ref & \\
\hline & Provincial & 0.99 & 0.92 to 1.07 \\
\hline & Remote, very remote, closed & 1.25 & 1.12 to 1.40 \\
\hline \multirow[t]{6}{*}{ Year level } & 1 & Ref & \\
\hline & 2 & 0.82 & 0.73 to 0.92 \\
\hline & 3 & 0.81 & 0.71 to 0.92 \\
\hline & 4 & 0.80 & 0.70 to 0.92 \\
\hline & 5 & 0.84 & 0.72 to 0.97 \\
\hline & 6 & 0.88 & 0.75 to 1.03 \\
\hline
\end{tabular}




\begin{tabular}{|c|c|c|c|}
\hline & & OR $^{*}$ & $95 \% \mathrm{Cl}$ \\
\hline & 7 & 1.01 & 0.86 to 1.20 \\
\hline & 8 & 1.45 & 1.18 to 1.78 \\
\hline & 10 & 3.75 & 3.02 to 4.66 \\
\hline Ever suspended & No & Ref & \\
\hline
\end{tabular}

*Adjusted for all other variables in the table and baby year of birth (matching variable).

\section{DISCUSSION}

As hypothesised, children whose mother had received a diagnosis of an alcohol use disorder were significantly more likely to be classified as having poor attendance compared with children whose mother did not have a diagnosis. This finding was consistent in both Indigenous and non-Indigenous cohorts. While any diagnosis of an alcohol use disorder was associated with poor school attendance, in the final models there was little difference between the timing of diagnosis relative to pregnancy and the strength of association with attendance outcomes. Of note, this finding differs from the result of previously published results for other types of adverse outcomes that make use of this cohort and the hierarchical classification of timing of alcohol diagnosis. O'Leary and colleagues identified that there was a significantly increased risk of birth defects and intellectual disability in children whose mother received an alcohol-related diagnosis during pregnancy, compared with children whose mothers received a diagnosis at other time points. ${ }^{23}{ }^{28}$ However, the results of the current study suggest that the relationship between exposure and attendance may not be driven by the biological effects of in utero alcohol exposure alone. This relationship may be mediated through family, social and environmental factors during pregnancy and/ or prepregnancy and postpregnancy, for which we were unable to adjust. While the data do not provide detailed information about the family or household circumstances prebirth or postbirth, previous research demonstrates that households with heavy parental alcohol use are at risk of instability, as well as concomitant risks such as abuse, poor family functioning, mental health problems and illicit substance use. ${ }^{131729}$ This is likely to be an environment in which school attendance is not prioritised. While results should be interpreted with caution, as an alcohol-related diagnosis does not capture all women who drink during pregnancy, these findings suggest that providing social support for vulnerable families may be effective in reducing child non-attendance.

In addition to maternal alcohol use, there were a number of sociodemographic factors that were associated with poor attendance. Indigenous children had substantially worse attendance than non-Indigenous students. This attendance gap is well recognised in the literature and exists in spite of targeted interventions that span a number of decades. ${ }^{30}$ This significant gap has been attributed to several factors, including greater family mobility, social and cultural reasons for absence, the higher rate of emotional and behavioural problems in Aboriginal children, the intergenerational legacy of past practices of exclusion of Aboriginal children from schools, and its impact on shaping family and community values regarding the importance of attending school in Indigenous families compared with non-Indigenous families. ${ }^{6731}$ Additional socioeconomic and school factors differed slightly between the Indigenous and non-Indigenous cohorts. However, low maternal age at child's birth, high parity and greater school mobility were consistently found to be associated with poor attendance. Further, it was evident that there was a strong relationship between type of school and attendance, with children in secondary school at greater odds of poor attendance compared with children attending primary school. This in part may be due to children leaving school to attend workplace training, alternative education pathways or greater autonomy in older age groups leading to increased truancy. However, it suggests that interventions to support children throughout their school career are needed to encourage higher rates of attendance and student retention through to school completion. Of note, in the Indigenous cohort, a diagnosis of a maternal mental health disorder or maternal record of illicit drug use in the administrative data sets was protective of poor attendance in the Indigenous cohort. While we are unable to investigate this further due to the nature of administrative data, this may reflect greater service use, increased likelihood of intervention or increased support for families with a mother who has been identified to have a mental health or history of illicit drug use.

The population attributable fraction provides an estimate of reduction in the poor attendance that would occur if maternal alcohol use disorder was eliminated. This was estimated to be $1.3 \%$ in the non-Indigenous population and $6 \%$ in the Indigenous population. While the population attributable fraction was substantially higher in the Indigenous population compared with the non-Indigenous, this was due to the higher prevalence of maternal alcohol use disorder in Indigenous mothers within the community. Therefore, we also aimed to quantify the impact of maternal alcohol use disorder 
Open Access

Table 7 Adjusted ORs for alcohol use disorder exposure, demographic and school factors significantly associated with $<60 \%$ attendance, Indigenous mothers

\begin{tabular}{|c|c|c|c|}
\hline & & $\mathrm{OR}^{*}$ & $95 \% \mathrm{Cl}$ \\
\hline \multirow[t]{6}{*}{ Alcohol diagnosis } & No alcohol diagnosis & Ref & \\
\hline & During pregnancy & 1.63 & 1.38 to 1.94 \\
\hline & $>1$ years postpregnancy & 1.63 & 1.48 to 1.79 \\
\hline & >1 year prepregnancy & 1.63 & 1.44 to 1.84 \\
\hline & Up to 1 year postpregnancy & 1.30 & 1.04 to 1.63 \\
\hline & Up to 1 year prepregnancy & 1.61 & 1.33 to 1.94 \\
\hline \multirow[t]{6}{*}{ Maternal age at child's birth } & $20-<25$ years & Ref & \\
\hline & $<20$ years & 1.37 & 1.24 to 1.51 \\
\hline & $25-<30$ years & 0.83 & 0.75 to 0.91 \\
\hline & $30-<35$ years & 0.78 & 0.69 to 0.88 \\
\hline & $35-<40$ years & 0.79 & 0.67 to 0.93 \\
\hline & $40+$ years & 1.06 & 0.67 to 1.67 \\
\hline \multirow[t]{3}{*}{ Marital status } & Married & Ref & \\
\hline & Never married & 1.16 & 1.07 to 1.25 \\
\hline & Separated, widowed, divorced & 0.96 & 0.76 to 1.22 \\
\hline \multirow[t]{5}{*}{ Socioeconomic status } & $>50 \%$ most advantaged & Ref & \\
\hline & $50 \%$ to $<75 \%$ & 1.06 & 0.90 to 1.24 \\
\hline & $75 \%$ to $<90 \%$ & 1.23 & 1.06 to 1.43 \\
\hline & Most disadvantaged $10 \%$ & 1.36 & 1.17 to 1.58 \\
\hline & Unknown & 1.71 & 1.47 to 2.00 \\
\hline \multirow[t]{2}{*}{ Health region } & Metropolitan & Ref & \\
\hline & Rural & 1.25 & 1.14 to 1.37 \\
\hline \multirow[t]{4}{*}{ Parity } & 0 & Ref & \\
\hline & 1 & 1.18 & 1.06 to 1.31 \\
\hline & 2 & 1.26 & 1.12 to 1.42 \\
\hline & $3+$ & 1.81 & 1.61 to 2.04 \\
\hline \multirow[t]{2}{*}{ Any maternal illicit drug record } & No & Ref & \\
\hline & Yes & 0.90 & 0.80 to 1.00 \\
\hline \multirow[t]{2}{*}{ Child protection contact } & No & Ref & \\
\hline & Yes & 0.89 & 0.81 to 0.98 \\
\hline \multirow[t]{3}{*}{ Number of schools } & One school & Ref & \\
\hline & Two schools & 2.25 & 2.11 to 2.41 \\
\hline & Three or more schools & 3.30 & 2.81 to 3.86 \\
\hline \multirow[t]{4}{*}{ School type } & Primary & Ref & \\
\hline & Combined & 1.65 & 1.50 to 1.81 \\
\hline & Secondary & 1.66 & 1.51 to 1.81 \\
\hline & Other & 1.08 & 0.78 to 1.48 \\
\hline \multirow[t]{5}{*}{ School area } & Metropolitan & Ref & \\
\hline & Provincial & 0.84 & 0.76 to 0.93 \\
\hline & Remote & 1.32 & 1.18 to 1.47 \\
\hline & Very remote & 1.62 & 1.45 to 1.80 \\
\hline & School closed & 1.76 & 1.25 to 2.48 \\
\hline \multirow[t]{2}{*}{ Year level } & 1 & Ref & \\
\hline & 2 & 0.81 & 0.73 to 0.90 \\
\hline
\end{tabular}

Continued 


\begin{tabular}{llll}
\hline & & OR $^{*}$ & $\mathbf{9 5 \%} \mathbf{C l}$ \\
\hline & 3 & 0.81 & 0.72 to 0.90 \\
& 4 & 0.67 & 0.59 to 0.76 \\
& 5 & 0.73 & 0.64 to 0.83 \\
& 6 & 0.77 & 0.67 to 0.89 \\
Suspension record & 7 & 0.91 & 0.78 to 1.05 \\
& 8 & 1.10 & 0.93 to 1.29 \\
& 9 & 1.73 & 1.46 to 2.06 \\
\hline & 10 & 2.28 & 1.90 to 2.74 \\
\hline
\end{tabular}

${ }^{*}$ Adjusted for all other variables in the model and baby year of birth (matching variable).

within the relatively small exposed population by estimating the percentage of days absent associated with maternal alcohol use disorder. We estimated the impact of maternal alcohol use disorder on total, unauthorised and authorised absences in the exposed populations. These results suggest that maternal alcohol use disorder predominantly impacts unauthorised absences, and the impact, when measured as the percentage of days absent, was greater in non-Indigenous children than in Indigenous children. While the greatest effect appeared to be on unauthorised absences, $8 \%$ of authorised absences in the non-Indigenous cohort could be attributed to maternal alcohol use disorder. Of note, while the population attributable fraction is higher in Indigenous cohorts, the impact is greater in non-Indigenous children. This finding supports the intervention programmes that target both parent and child school engagement to reduce child non-attendance.

\section{Strengths and limitations}

A key strength of the project is the use of administrative data, which avoids the use of self-reports of drinking behaviours, which may be biased due to retrospective recall and social desirability. Further, we can be confident that mothers who received an alcohol-related diagnosis were consuming alcohol at very high levels. However, we have no information about the level of dependency, periods of sobriety or ongoing maternal alcohol use following a diagnosis. Further, it is important to note that it is likely that there are a number of children who were exposed to significant amounts of maternal alcohol use (as evidenced by the presence of cases of fetal alcohol spectrum disorder in the comparison cohort), and the associated social and environmental effects, which were not identified in the data set. This dilution of the comparison group is likely to bias the findings towards the null. In addition, paternal factors, detailed maternal polydrug use, comorbidities, the family environment and additional unmeasured confounders not captured by administrative data sets cannot be included in the analysis. Therefore, it is difficult to ascertain all the underlying reasons for school non-attendance. Additional work is required to determine the reasons for non-attendance in families where there are maternal alcohol use problems in order to develop and target effective interventions.

\section{CONCLUSIONS}

The causes of non-attendance are complex. However, this study indicates that a child whose mother has an alcohol-related diagnosis is significantly more likely to have poor attendance problems than children whose mother does not have a diagnosis. The strength of the association of poor school attendance was similar at each of the diagnostic time periods. This differs from previous studies that use this cohort, where exposure in pregnancy had a significantly greater effect on other types of adverse child outcomes. ${ }^{23} 28$ These findings may indicate that the relationship between school attendance and maternal alcohol use disorders is not primarily driven by the neurobehavioural effects of alcohol during pregnancy, but rather a complex family and social environment in which school attendance is not a priority or not well monitored. Ongoing prepregnancy counselling regarding the impact of alcohol use on the offspring, as well as ongoing education, treatment and support regarding problematic or risky drinking behaviours throughout pregnancy and parenthood, is imperative. In addition, further research regarding why women continue to consume significant amounts of alcohol in these time periods despite health recommendations, as well as more effective methods to target, educate and support these women, is needed. Finally, detailed and mandatory data collection regarding alcohol use during pregnancy would improve the ability to intervene during pregnancy or postpregnancy and improve the quality of research and understanding regarding alcohol use and child outcomes.

Contributors CO, CB, JS and SRZ conceptualised the study and obtained funding. $\mathrm{KH}$ completed the analysis and drafted the manuscript. DL provided expert 
advice, both in statistical analysis and the drafting of the manuscript. All authors contributed to the final manuscript.

Funding The project is funded by an Australian Research Council Discovery Project (Project ID DP140101573).

Competing interests None declared.

Patient consent Detail has been removed from this case description/these case descriptions to ensure anonymity. The editors and reviewers have seen the detailed information available and are satisfied that the information backs up the case the authors are making.

Ethics approval WA Department of Health Human Research Ethics Committee. Provenance and peer review Not commissioned; externally peer reviewed.

Data sharing statement Data were provided by the Western Australian Department of Health, Data Linkage Branch. This information is confidential, and authors are bound by confidentiality agreements which prevent data sharing.

Open Access This is an Open Access article distributed in accordance with the Creative Commons Attribution Non Commercial (CC BY-NC 4.0) license, which permits others to distribute, remix, adapt, build upon this work non-commercially, and license their derivative works on different terms, provided the original work is properly cited and the use is non-commercial. See: http://creativecommons.org/ licenses/by-nc/4.0/

(c) Article author(s) (or their employer(s) unless otherwise stated in the text of the article) 2017. All rights reserved. No commercial use is permitted unless otherwise expressly granted.

\section{REFERENCES}

1. Hancock KJ, Shepherd CC, Lawrence D, et al. Student attendance and educational outcomes: every day counts. Report for the Department of Education, Employment and Workplace Relations, Canberra, 2013.

2. Dube SR, Orpinas P. Understanding Excessive School Absenteeism as School Refusal Behavior. Child Sch 2009;31:87-95.

3. Daraganova G, Mullan K. No. 51: attendance in primary school: factors and consequences. Canberra: Australian Government Department of Social Services, 2014.

4. Kearney CA. School absenteeism and school refusal behavior in youth: a contemporary review. Clin Psychol Rev 2008;28:451-71.

5. Romero M. Lee Y. A National Portrait of chronic absenteeism in the early grades. New York National Center for Children in Poverty, Columbia University, 2007.

6. Zubrick SR, Silburn SR, De Maio JA, et al. Western Australian Aboriginal Child Health survey: improving the Educational experiences of Aboriginal children and Young people. Perth: Curtin University of Technology and Telethon Institute for Child Health Research, 2006.

7. Purdie N, Buckley S. School Attendance and Retention of indigenous australian students. Issues Paper No. 1: ERIC 2010.

8. Helme S, Lamb S. Closing the School Completion gap for indigenous students. Resource Sheet No. 6. Australian Institute of Health and Welfare 2011.

9. Moore T, McArthur M. If only I, they, we had done things differently: young people talk about school difficulties and crime. Child Youth Serv Rev 2014;44:249-55.

10. Vall O, Salat-Batlle J, Garcia-Algar O. Alcohol consumption during pregnancy and adverse neurodevelopmental outcomes. $J$ Epidemiol Community Health 2015;69:927-9.

11. Goldschmidt L, Richardson GA, Stoffer DS, et al. Prenatal alcohol exposure and academic achievement at age six: a nonlinear fit. Alcohol Clin Exp Res 1996;20:763-70.
12. Mattson SN, Riley EP. A Review of the Neurobehavioral Deficits in Children with Fetal Alcohol Syndrome or Prenatal Exposure to Alcohol. Alcoholism: Clinical and Experimental Research 1998;22:279-94.

13. Hutchinson DM, Mattick RP, Danya B, et al. The impact of alcohol use disorders on family life: a review of the empirical literature: National Drug and Alcohol Research Centre, University ofNew South Wales, 2014.

14. Burke S, Schmied V, Montrose M. Parental alcohol misuse and the impact on children - A literature review: research, Funding \& Business Analysis Division. Centre for Parenting \& Research 2006.

15. Dawe S, Harnett P, Frye S. Improving outcomes for children living in families with parental substance misuse: what do we know and what should we do. National Child Protection Clearinghouse, 2008.

16. Sarkola T, Kahila H, Gissler M, et al. Risk factors for out-of-home custody child care among families with alcohol and substance abuse problems. Acta Paediatr 2007;96:1571-6.

17. Burns L, Teesson M, Lynskey M. The epidemiology of comorbidity between alcohol use disorders and mental disorders in Australia. National Drug and Alcohol Research Centre.

18. Kahila H, Gissler M, Sarkola T, et al. Maternal welfare, morbidity and mortality 6-15 years after a pregnancy complicated by alcohol and substance abuse: a register-based case-control follow-up study of 524 women. Drug Alcohol Depend 2010;111:215-21.

19. Casas-Gil MJ, Navarro-Guzman Jl. School characteristics among children of alcoholic parents. Psychol Rep 2002;90:341-8.

20. Hill NE, Taylor LC. Parental School Involvement and Children's Academic Achievement. Curr Dir Psychol Sci 2004;13:161-4.

21. Barton AC, Drake C, Perez JG, et al. Ecologies of parental engagement in Urban Education. Educational Researcher 2004;33:3-12.

22. Peters M, Ken Seeds K, Goldstein A, et al. Parental involvement in children's education 2007. BMRB Social Research, Department for children, schools and families, 2008.

23. O'Leary $\mathrm{C}$, Leonard $\mathrm{H}$, Bourke $\mathrm{J}$, et al. Intellectual disability: population-based estimates of the proportion attributable to maternal alcohol use disorder during pregnancy. Dev Med Child Neurol 2013;55:271-7.

24. O'Leary CM, Watson L, D'Antoine $\mathrm{H}$, et al. Heavy maternal alcohol consumption and cerebral palsy in the offspring. Dev Med Child Neurol 2012;54:224-30.

25. Holman CD, Bass AJ, Rouse IL, et al. Population-based linkage of health records in Western Australia: development of a health services research linked database. Aust N Z J Public Health 1999;23:453-9.

26. Australian Bureau of Statistics. 4221.0 - Schools Australia 2012. http://www.abs.gov.au/AUSSTATS/abs@.nsf/Previousproducts/ 4221.0Main\%20Features202012?opendocument\&tabname= Summary $\&$ prodno $=4221.0 \&$ issue $=2012 \&$ num $=\& v i e w=($ accessed Mar 2017).

27. Blair EM, Liu Y, de Klerk NH, et al. Optimal fetal growth for the Caucasian singleton and assessment of appropriateness of fetal growth: an analysis of a total population perinatal database. BMC Pediatr 2005;5:1.

28. O'Leary CM, Elliott EJ, Nassar N, et al. Exploring the potential to use data linkage for investigating the relationship between birth defects and prenatal alcohol exposure. Birth Defects Res A Clin Mol Teratol 2013;97:497-504.

29. Jacobson SW, Chiodo LM, Sokol RJ, et al. Validity of maternal report of prenatal alcohol, cocaine, and smoking in relation to neurobehavioral outcome. Pediatrics 2002;109:815-25.

30. Gray J, Beresford Q. A ?Formidable Challenge?: Australia's Quest for Equity in Indigenous Education. Aust J Educ 2008;52:197-223.

31. Bourke CJ, Rigby K, Burden J. Better practise in school attendance: improving the school attendance of indigenous students. Monash University for Commonwealth Department of Education Training and Youth Affairs, 2000. 